\title{
Nanogram per Milliliter per Kilogram per Meter Squared
}

National Cancer Institute

\section{Source}

National Cancer Institute. Nanogram per Milliliter per Kilogram per Meter Squared. NCI Thesaurus. Code C119444.

A unit of concentration equal to nanograms per milliliter, divided by kilograms per meter squared. 